Dept. of Surgery,

Fac. of Vet. Med., Assiut University,

Head of Dept. Prof. Dr. N.A. Misk.

\title{
COMPARISON OF POLYDIOXANONE \\ AND POLYGLYCOLIC ACID SUTURES FOR CLOSURE OF ARTHROTOMY INCISIONS IN DONKEYS \\ (With 6 Figures)
}

By

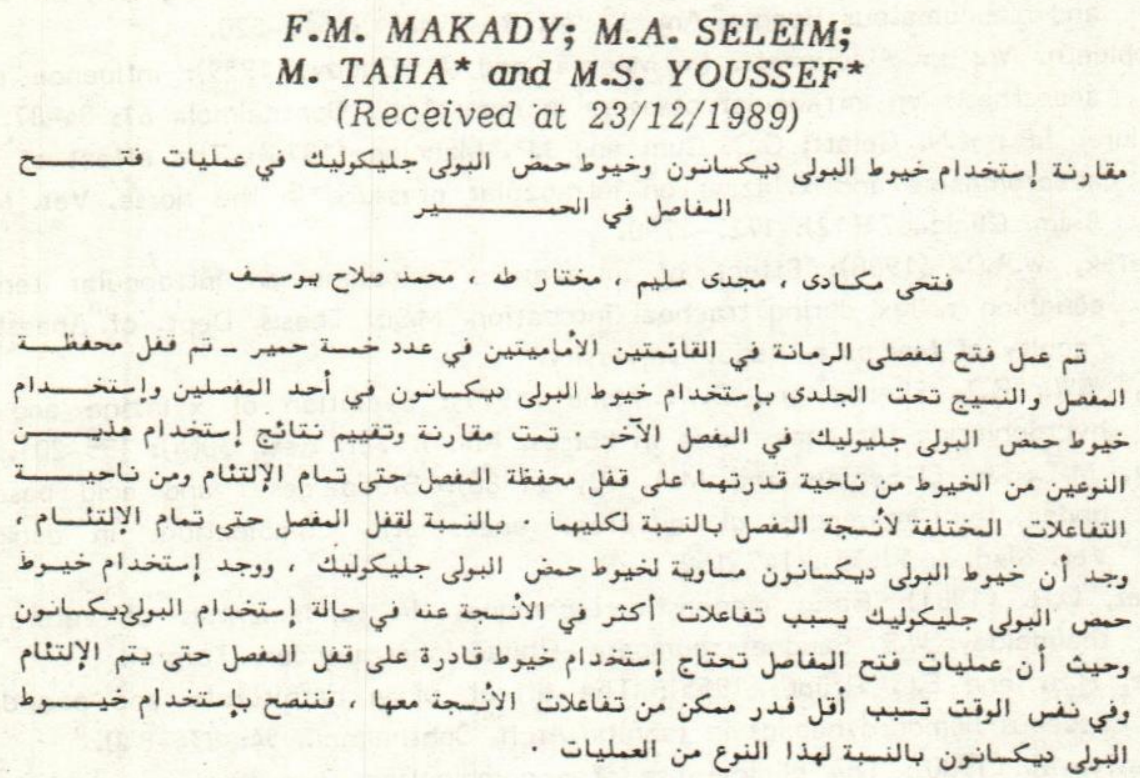

\section{SUMHARY}

Arthrotomy incision was made on both front fetlock joints of five donkeys. The joint capsule and subcutaneous tissue were closed with polydioxanone suture material (PDS) in one joint and sutured with polyglycolic acid suture material (dexon) in the other joint. The materials were compared and evaluated for security of closure until healing was completed as well as the various tissue responses. Polydioxanone suture was related equal to polyglycolic acid for security of closure. The latter evocked greater tissue responses, when compared with polydioxanone suture.

Because of the requirments of suture to retain its strength while exciting a minimal amount of scar tissue during healing, PDS seemed a good. choice for closure of arthrotomy incisions.

*: Dept. of Patholog, Fac. of Vet. Med., Assiut Uniersity.

Assiut Vet.Med.J. Vol. 23, No. 46, 1990. 


\section{F.M. MAKADY et al.}

\section{INTRODUCTION}

The tissue of the equine joint capsule is bradytrophic, or slow to heal. CANNON (1969) reported that the degree of healing in 14 days after surgery ranged from complete healing to almost none in surgically incised equine fetlock joints. Equine joints heal with formation of dense scar tissue that may lead to joint stiffness and a decrease in the range of motion (MITCHELL and BLACKWELL, 1968). The ideal suture material for use in capsular tissue would have these characteristics: minimal inflammatory and foreign body reaction, yet able to maintain strength for a sufficient period to keep wound edges together untile healing is complete (CANNON, 1969).

Polyglycolic acid exhibit a duration of maximum tensile strength which is twice that of other absorbable sutures (BERRY et al., 1981). It is slowly absorped and excite a very low foreign body reaction when placed in subcuticular or muscular tissue (ANSCOMBE et al., 1970). Polydioxonone is a more recently developed polymer of para-dioxanone that can be converted into a flexable monofilament, suitable for all sizes of suture material. Clinical tests have showen polydioxanone to be useful in a variety of tissues and procedures (Ray et al., 1981).

The aim of this study is to compare polydioxanone (PDS) a synthetic absorpable suture material with polyglycolic acid (Dexon) for use in donkeys arthrotomies. The materials were compared and evaluated for security of closure as well as the micromorphologic evaluation of the various tissue responses.

\section{MATERIAL and METHODS}

Five healthy donkeys, ranging in age from 3-5 years, were used. Arthrotomy incisions were made in both front fetlock joints of each donkeys. The operations were performed under the effect of deep chloral hydrate narcosis, following premedication with i.m. injection of combelen $(0.25 \mathrm{mg} / \mathrm{Kg}$. B.W.). In each animal, 2-0 polydioxanone suture (PDS: Ethicon) was used for closure of the joint capsule and subcutaneous tissues of the right front fetlock joint (Group I, $n=5$ ). 2-0 polyglycolic acid (Dexon: Davis \& Geck) was used for closure of the joint capsule andsubcutaneous tissues of the left front fetlock joint (Group II, $n=5$ ).

The donkey was placed in lateral recumbency, Esmarch's tourniquet was appilied below the carpal joint. The animal was prepared for aseptic surgery of both front fetlock joints. A skin incision approximately $5 \mathrm{~cm}$. long was made $1 \mathrm{~cm}$. medial to the common digital extensor tendon over the fetlock joint. The subcutaneous fascia was incised along the same line as the skin incision. The incision was continued deep through the joint capsule. In both joints, the fibrous joint capsules were closed with horizontal mattres sutures. The tourniquet was removed and the small bleeders in the sucutaneous tissue were stopped. The subcutaneous tissues were closed with simple continuous pattern. An interrupted pattern was used to close the skin.

The wounds were covered with nonadherent dresings and bandages which were changed at 5, 10 and 15 days post-surgery. 
JOINT HEALING IN DONKEYS

On days $7,14,21,28$ and 35 after surgery one donkey was humanely euthanized and the appearance of the wound evaluated. Tissues from the incision site ot the joint capsule were harvested and submitted for histopathological evaluation.

The tissue speciemens were fixed in neutral buffered formaline and prepared by the conventional techniques for microscopic examination.

\section{RESULTS}

Gross observation of healing of the arthrotomy incisions of both front fetlock joints revealed that there was incomplete healing at 7 days. Wound dehiscence, local heat, swelling and lameness associated with septic arthritis were not evident. By 14 days the healing was completed. In group I there was complete satisfactory healing of the incisions with minimal tissue thickening at 21,28 and 35 days. In group II, the examination revealed the presence of minimal joint distention and discernible soft tissue thickening at the surgical sites. This thickening was most prominent on days 21,28 and 35 .

One week post-surgery, the joint capsule sutured with PDS showed focal areas of necrosis at the wound edges. Between the necrosed edges, partially absorbed blood clot and few aggregations of neutrophils were observed. At the same time, an early granulation tissue formation was commensed at the vascularization sites of the tendenious part of the joint capsule (Fig. 1 ). Such granulation tissue was composed mainly of newly formed capillaries and few fibroblast cells. The acute inflammatory phenomenon appeared in the form of few neutrophilic and lymphocytic aggregates. Apart from the area of granulation, the other collagenous tissue of the joint capsule appeared oedematous and showed few haemorrhages as well as lymphocytic infiltrates.

After 2 weeks, an advanced granulation tissue expressed by highly proliferated fibroblasts, increased fibrous elements and decreased vascularity could be noticed at the incision site (Fig. 2). At 3 weeks, such granulation tissue transformed into mature collagenous bundles and fibrocytic cells. However at the wound edges, it showed areas of myxomatous degeneration (Fig. 3). On the other hand, the suture material was invaded by mononuclear cellular infiltrates and proliferated giant cells. Such process resulted in partial lysis and absorption of the suture material (Fig. 4).

After 4 weeks, some suture material appeared surrounded by healthy mature fibrous tissue at one side, while the other side was encircled by the original collagen bundles of the joint capsule. Apart from the stitches, the wound incision healed through granulation tissue formation which closed the wound edges. At Sth week, the majority of the suture material was absorbed and healing occurred by mature fibrous tissue.

Microscopic observations of the jont capsule sutured with Dexon, one week post-surgery, didn't differ from that sutured with PDS. However, few eosinophilic infiltrations could be found at the site of granulation tissue formation.

Assiut Vet.MedJ. Vol. 23, No. 46, 1990. 
F.M. MAKADY et ai.

Fig. (1): Early granulation tissue formation. (PDS, one week, H\&E, X 160).

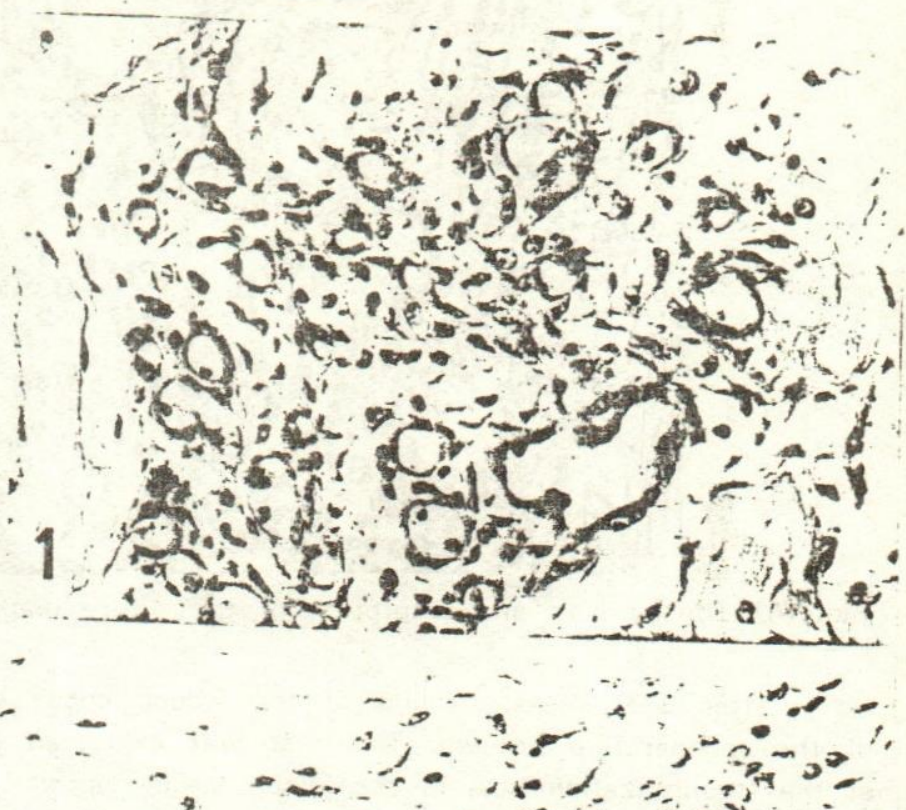

Fig. (2): Advanced granulation tissue (PDS, 2 weeks, H\&E, $\times$ 400).

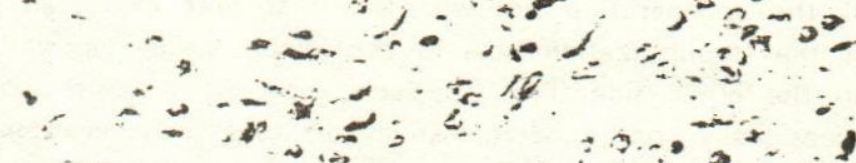

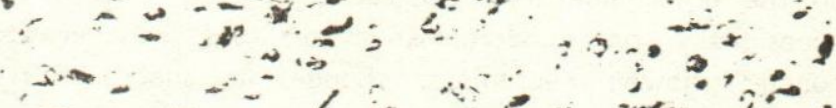

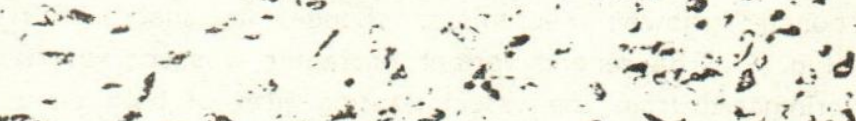

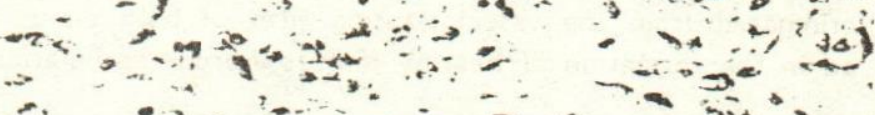

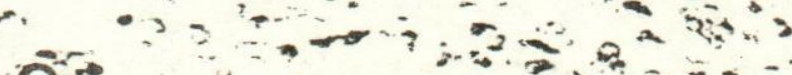

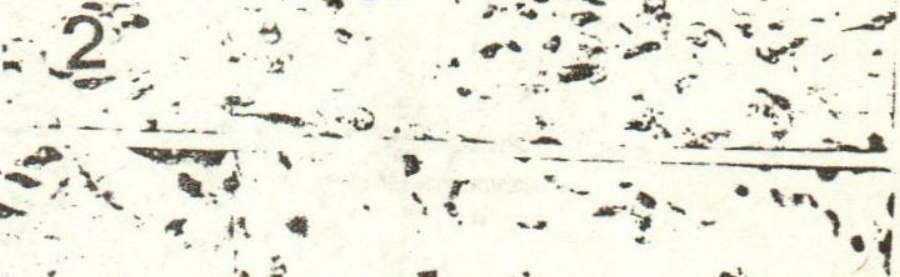

Fig. (3): Myxomatous degeneration of the granulation tissue (PDS, 2 weeks, H\&E, $X$ 400). 
JOINT HEALING IN DONKEYS

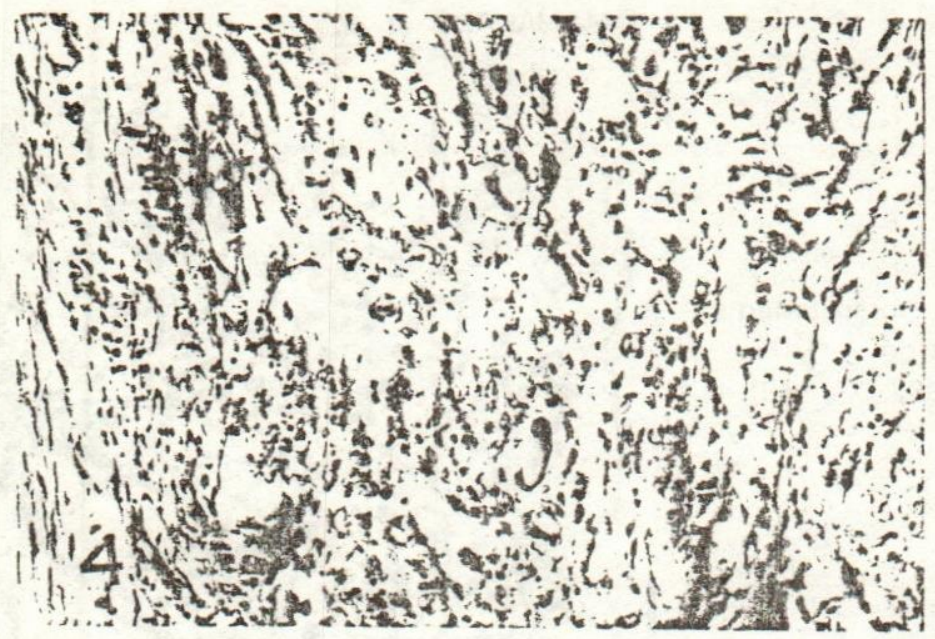

Fig. (4): Partial lysis and absorption of the suture materiai (PDS, 3 weeks, H\&E,X250).

After 2-3 weeks, healing of the wound edges exhibited two variable patterns of the regenerative process. The first was expressed by granulation tissue formation at the vascularization sites of the joint capsule opposite to the original collagen bundles on the other side (Fig. 5). Such granulation tissue showed retardation in growth and occasionally had undergone myxomatous degeneration. In addition, the collagenous bundles showed necrobiotic changes associated with mononuclear cellular infiltration (Fig. 6). The second variant of repair was characterized by granulation tissue formation originated from the vascularization sites of both edges of the wound incision. It resulted in the formation of healthy mature fibrous granulation tissue.

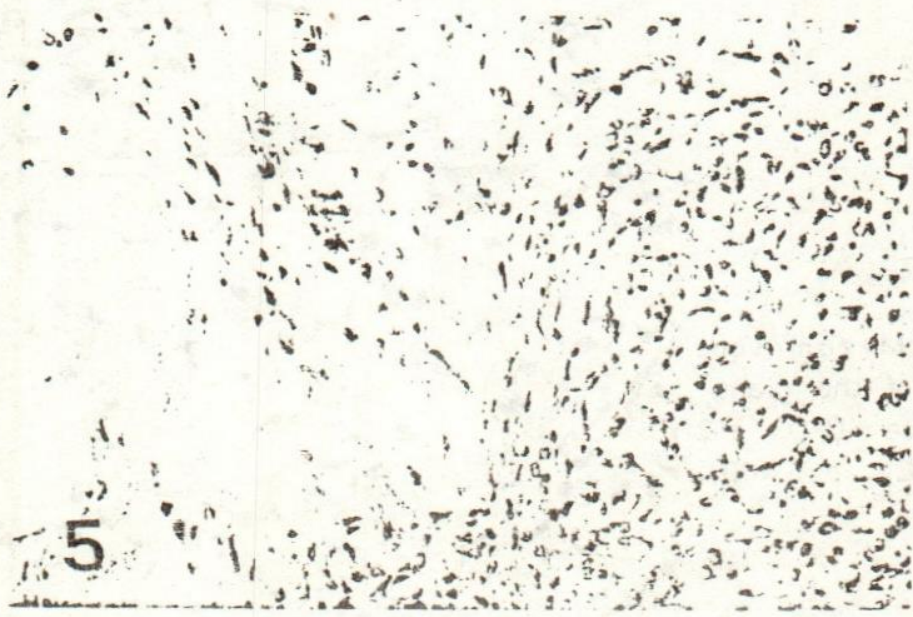

Fig. (5): Wound edges healed by granulation tissue at one side and collagen at the other (Dexon, 3 weeks H\&E, X 250).

Assiut Vet.Med_. Vol. 23, No. 46, 1990. 
F.M. MAKADY et al.

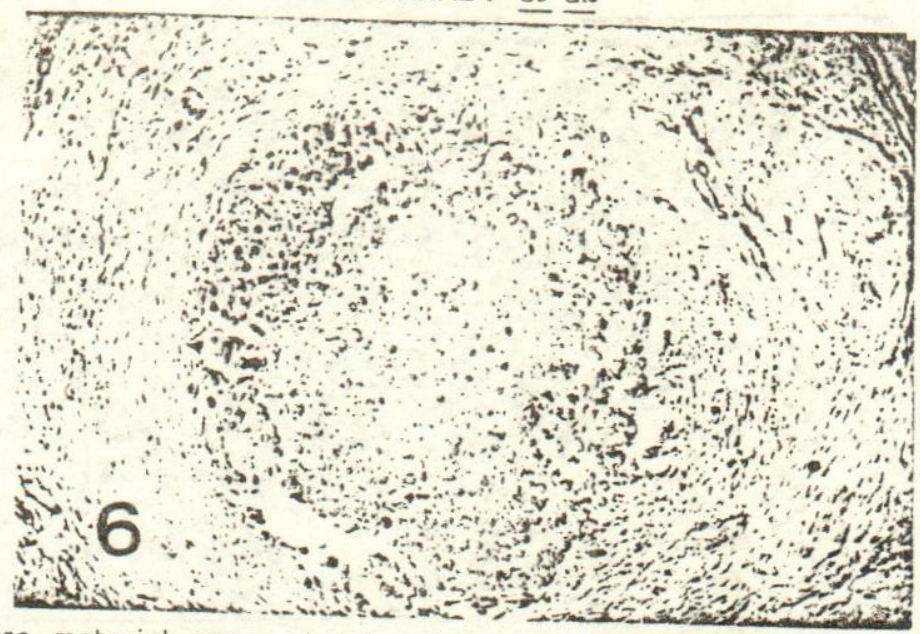

Fig. (6): Suture material surrounded by dense fibrous connective tissue capsule (Dexon, 5 weeks, H\&E, $\times$ 65).

On evaluation of the tissue response to Dexon material at 3-5 weeks postsurgery, the common picture of tissue reaction to suture material was characterized by unabsorption of the stitches together with granulation tissue formation. The majority of the examined cases showed encircling of the stitches by a mature fibrous connective tissue Fig. 6). However, in some cases, the suture material was surrounded by retarded granulation tissue from one side and collagenous bundles from the other dside (Fig. 7). In such cases, the collagenous bundles appeared necrotic and were associated with inflammatory cellular reaction ( $F$ ig. 8 ),

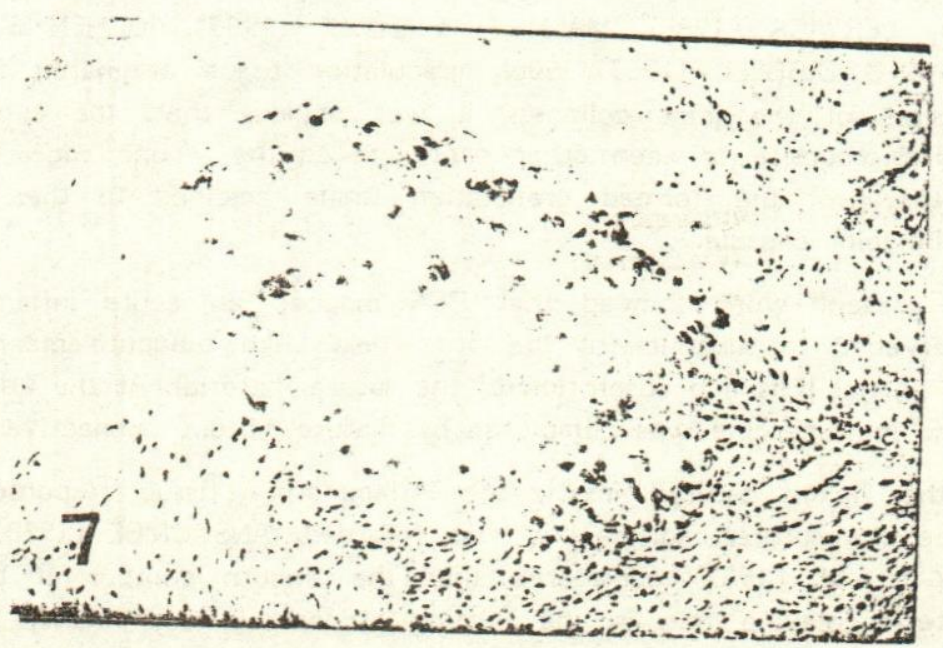

Fig. (7): Suture material surrounded by retarded granulation and degenerated collagen
(Dexon, 3 weeks, H\&E, $x$ 160).

Assiut Vet.Med.J. Vol. 23, No. 46, 1990. 
JOINT HEALING IN DONKEYS

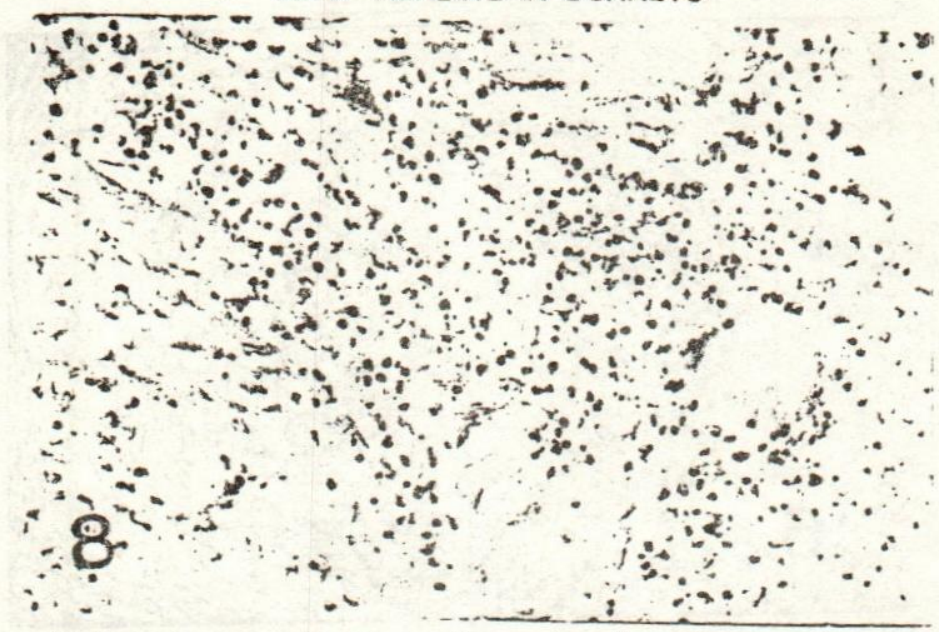

Fig. (8): Necrobiotic changes of the collagen bundles (Dexon, 3 weeks, H\&E, X 400).

\section{DISCUSSION}

Fetlock joint is one of the most mobile joints in the equine skeletal system and the resultant movements and stress play a role in the capsular wound disruption (CANNON, 1969).

In the prsent study, although the clinical evaluation of the arthrotomized joints revealed complete healing at 14 days, the hsito-anatomical nature of the joint capsule influenced the regenerative process. In both PDS and Dexon-treated groups, healing of the joint capsule took place by granulation tissue formation. Similar results were recorded by LERWICK (1983), MALNATI \& STONE (1983), JOCHEN \& SWITES (1984), and CHUSAK \& DIBBELL (1983). Such granulation tissue originated from the vascularization sites of the joint collagen. It was obvious that, the occasional presence of these sites opposite to each other approximated the wound edges and healing was perfect. Otherwise, the formed granulation tissue adjoined to the original collagen bundles of the joint capsule.

The present work showed that PDS induced an acute inflammatory reaction which supervened to subacute at the 3 rd week. Such subacute macrophagal reaction resulted in partial lysis and absorbtion of the suture material. At the 4th week, regeneration of the joint capsule was completed by mature fibrous connective tissue formation.

In the Dexon sutured joints, the inflammatory tissue response failed to lyse and absorbe the sutures, so, healing was retarded. ANSCOMBE (1970), BERRY (1981) and KIRBY et al. (1989) considered that the smooth contour of the monofilament suture material play a role in the healing process. In our findings, such probability seemed of no importance. In the Dexon-sutured group, the formed granulation was retarded in growth and the joint collagen showed myxomatous degeneration. Such changes may be attributed to the persistence of the suture material which acted as a chronic traumatic irritant to the joint capsule.

Assiut Vet.Med.J. Vol. 23, No. 46, 1990. 


\section{F.M. MAKADY et al.}

In conclusion, the fate and effect of Dexon material was quite different from PDS. PDS seemed a good choice for wound regeneration and is recommended for
suturing of joints.

\section{REFERENCES}

Anscombe, A.R.; Hira, N. and Hunt, B. (1970): The use of a new absorbable sutture material (Polyglycolic acid) in general surgery. British Journal of Surgery, 57,

Berry, A.R.; Wilson, M.C.; Thomson, J.W. and McNair, T.J. (1981): Polydixanone: a new synthetic absorbable suture. J. Rowal Col Surg of Edinburgh 26(3): 170-172. Cannon, J. (1969): An Investigation of Healing Following Arthrotoy of the Equine Fetlock.
Proc 20th AAEP, pp 233-235.

Chusak, R.B. and Dibbell, D.G. (1983): filament absorbable suture in plasticnical experience with polydioxanone monoJochen, R.F. and Swites, B.J. (1984): Vlast Reconstr Surg 72: 217-221. suture materials. Vet. Med. 79: 969-972.

Kirby, B.M.; Knoll, J.S.; Manley, P.A. and Mile Associated With Polydioxanone Suture in, L.M. (1989): Calcinosis Circumscripta 216-220. absorbable sutrue. Surg. Syne efficacy and safety of polydioxanone monofilament

Malnati, G.A, and Stone, E.A. material. Vet. Surg., 12: 24-25. Clinical experience with polydioxanone suture

Mitchell, N. and Blackwell,

vium After Subtotal Synovecto: The electron Microscopy of Regenerating SynoRay, J.A.; Doddi, N. and Reguvectomy in Rabbits. J. Bone Jt. Surg., 50-A: 675. synthetic absorbable suture. 